\title{
Direct and Indirect Effects of Calcium Entry Blocking Agents on Isovolumic Left Ventricular Relaxation in Conscious Dogs
}

Richard A. Walsh and Robert A. O'Rourke

Department of Medicine, The University of Texas Health Science Center at San Antonio, Veteran's Administration Hospital, San Antonio, Texas 78284

\begin{abstract}
To assess the direct and indirect effects of the commonly used calcium entry blockers (CEB) upon the major determinants of isovolumic left ventricular relaxation, we administered equidepressant intracoronary (IC, $n=7)$ and equihypotensive intravenous $(n=12)$ dosages of diltiazem $(16 \pm 3 \mathrm{SE} \mu \mathrm{g} / \mathrm{kg} \mathrm{IC}$ and $63 \pm 9 \mu \mathrm{g} / \mathrm{kg}$ i.v.), verapamil $(10 \pm 2$ and $57 \pm 5 \mu \mathrm{g} / \mathrm{kg})$, and nifedipine $(1 \pm 0.1$ and $8 \pm 0.3 \mu \mathrm{g} / \mathrm{kg})$ to preinstrumented awake dogs with normal ventricular function. The time constant of left ventricle $(\mathrm{LV})$ relaxation, analyzed by two methods $\left(T_{1}\right.$, from the linear relation of the natural logarithm of $\mathrm{LV}$ pressure and time; $T_{2}$, from the linear relation of $L V$ pressure and negative high fidelity $L V$ pressure), was significantly and equivalently prolonged by IC diltiazem $\left(T_{1}+48 \%, P<0.02\right)$, verapamil $\left(T_{1}+43 \%, P<0.001\right)$, and nifedipine $\left(T_{1}+30 \%\right.$, $P<0.03)$. Lesser amounts of each CEB that did not affect rate of $\mathrm{LV}$ pressure development or extent of shortening produced no change in $T_{1}$ or $T_{2}$. By contrast, intravenous calcium entry blockade either produced no significant change (diltiazem and verapamil) or shortened (nifedipine $T_{1}-18 \%$, $P<0.01) \mathrm{LV}$ isovolumic relaxation. However, after beta adrenergic blockade with propranolol $(2 \mathrm{mg} / \mathrm{kg}$ i.v., $n=6)$ no change in ventricular relaxation was observed during nifedipine and the time constant was significantly prolonged by verapamil $\left(T_{1}+15 \%, P<0.05\right)$.

We conclude that calcium entry blockade directly impairs normal left ventricular relaxation: This effect is closely linked to the negative inotropic properties of these drugs. The prolongation of isovolumic relaxation produced by calcium blockade is attenuated or even reversed by reflex sympathetic stimulation and favorably altered loading conditions during systemic administration.
\end{abstract}

\section{Introduction}

Calcium entry blocking drugs are now widely used in the treatment of a variety of cardiovascular disorders (1). There have been many studies concerning the effects of these agents on systolic ventricular performance (2-6) in preinstrumented conscious dogs, but little is known about their effects upon normal diastolic properties of the left ventricle. In particular, the potential role of the reduction of transcellular myocardial calcium influx by pharmacologic calcium entry blockade in modulating left ventricular pressure decay is unclear.

\footnotetext{
Address correspondence to Dr. Walsh, Division of Cardiology.

Received for publication 9 October 1984 and in revised form 22 January 1985
}

J. Clin. Invest.

(C) The American Society for Clinical Investigation, Inc.

0021-9738/85/05/1426/09 \$1.00

Volume 75, May 1985, 1426-1434
Several clinical investigations $(7-9,9 a)$ have suggested that calcium entry blockers (CEB) ${ }^{1}$ may enhance ventricular relaxation in patients with hypertrophic cardiomyopathy or ischemic heart disease, and thus contribute to clinical improvement of such patients. However, the mechanism of these salutary effects is uncertain because of the difficulties encountered in distinguishing the relative contribution of reflex sympathetic stimulation, altered ventricular loading, and direct myocardial effects evoked by these agents on the relaxation process (10). There is also no information available regarding the relative effects of the commonly used calcium entry blocking agents upon isovolumic left ventricular relaxation. We designed the present investigation to assess the effects of calcium entry blockade upon the major determinants of normal myocardial relaxation, and to assess the comparative effects of the commonly used calcium channel blockers diltiazem, verapamil, and nifedipine on the ventricular relaxation process.

\section{Methods}

Canine preparation. 19 healthy adult mongrel dogs $(18-30 \mathrm{~kg})$ were surgically instrumented for long term physiologic monitoring by methods previously described for this laboratory (11). Dogs were premedicated with xylazine and pentobarbital $(15 \mathrm{mg} / \mathrm{kg})$. Endotrachial intubation was performed and the dogs were ventilated with $1.5 \%$ halothane anesthesia. The chest was opened in the fifth left intercostal space under sterile conditions. The pericardial sac was incised parallel to the phrenic nerves and left widely open. Polyvinyl 16-gauge catheters were implanted in the descending aorta, apical left ventricle (LV), and superior vena cava. A solid state micromanometer pressure transducer (P-18, Konigsberg Instruments, Inc., Pasadena, CA) was placed in the apex of the LV. Seven of these dogs (group I) were instrumented with proximal circumflex coronary artery catheters for intracoronary (IC) drug administration (4) and miniature $2 \mathrm{~mm}$ subendocardial ultrasonic segment gauge pairs for measuring percentage of regional myocardial shortening in the circumflex area (LV base) as determined by the area of cyanosis produced by transient coronary occlusion during instrumentation. These animals also had regional segment crystal pairs similarly placed in the area perfused by the left anterior descending coronary artery (LV apex). The regional ultrasonic crystal pairs were aligned perpendicular to the long-axis and parallel to circumferential hoop fibers of the LV wall close to the endocardium according to the method of Franklin et al. (12).

In the remaining 12 dogs (group 2), two $5-\mathrm{mHz}$ piezoelectric crystals $(4 \mathrm{~mm}$ in diameter) were also implanted along the greatest internal left ventricular transverse diameter, one on the anterior and the other on the posterior endocardial wall for continuous measurement of LV internal dimension and global percentage of shortening (13) in

1. Abbreviations used in this paper: ANOVA, analysis of variance; CEB, calcium entry blocker(s); dP/dt, first derivative of high fidelity LV pressure; IC, intracoronary; LV, left ventricle; LVEDP, left ventricular end-diastolic pressure; $\mathrm{PB}$, pressure axis intercept; $T$, time constant of exponential left ventricular pressure fall after $\mathrm{dP} / \mathrm{dt}$ max; $T_{1}$, value of $T$ calculated from the logarithm of pressures; $T_{2}, T$ calculated from the first derivative of pressure. 
lieu of regional crystal pairs. In six of these dogs, electromagnetic cuff type flow probes (Zepeda Instruments, Seattle, WA) were placed around the ascending aorta. All wires and tubes were tunneled subcutaneously to the back of the neck and dogs were allowed to recover for a minimum of $2 \mathrm{wk}$ before experimentation.

Data collection. Each study was performed with the dog lying quietly on the right side in a sling. The left ventricular and aortic catheters were connected to Statham P23DB pressure transducers precalibrated with a mercury manometer using the vertebral column as the zero reference point and atmospheric pressure as the zero reference. The left ventricular pressure signal from the micromanometer was adjusted to match that obtained from the fluid-filled catheter. The first derivative of left ventricular pressure was obtained electronically from the micromanometer signal using an RC circuit with a linear frequency response to $70 \mathrm{~Hz}$ and $3 \mathrm{~dB}$ down at $100 \mathrm{~Hz}$. The transit time of $5 \mathrm{mHz}$ ultrasound between ultrasonic crystal pairs was measured with a multichannel sonomicrometer (Scheussler and Assoc., San Diego, CA) using the electronics of Franklin (12) and was converted to distance assuming constant velocity of sound in blood of $1.55 \mathrm{~mm} /$ $\mu \mathrm{s}$. The resolution of this system has been reported at $0.07 \mathrm{~mm}$ with $5-\mathrm{mHz}$ signals (13). High fidelity and fluid LV pressure, the first derivative of high fidelity $\mathrm{LV}$ pressure $(\mathrm{dP} / \mathrm{dt})$, aortic pressure, aortic flow velocity, and the dimensions of regional (group 1) or transverse LV diameter (group 2) ultrasonic crystal pairs were recorded on an 8 channel forced-ink pen oscillograph (Beckman Instruments Inc., Fullerton, CA) at a paper speed of $25 \mathrm{~mm} / \mathrm{s}$. The analogue signals were also digitized with an on-line analogue to digital convertor (Dual Control Systems, Los Angeles, CA) at 5-ms intervals and stored on floppy discs using a minicomputer system (Zobex Systems, Los Angeles, CA) and software developed in our laboratory.

Data analysis. Data were analyzed by means of computer algorithm. End-diastolic transverse dimension and segment length were defined as the distance between ultrasonic crystal pairs at the Z-point of the high fidelity left ventricular pressure signal or as the LV pressure at which $+\mathrm{dP} / \mathrm{dt}$ increased by $150 \mathrm{mmHg} / \mathrm{s}$ with the increase sustained for at least $50 \mathrm{~ms}$ when no A wave was present at higher heart rates. End-systolic lengths were measured at the minimum intercrystal distance before (-)dP/dt max, which corresponds to maximal segmental shortening during left ventricular ejection in the normal left ventricle (14, 15). In all experiments, both during the control state and during the peak effect of each IC calcium entry blocker, the minimum regional segment end-systolic dimension occurred before $(-) \mathrm{dP} / \mathrm{dt} \max$. Percentage of shortening of the $\mathrm{LV}$ transverse diameter signal and regional shortening were calculated as the end-diastolic length minus the endsystolic length divided by the end-diastolic length times 100. Cardiac output was measured as the product of the stroke volume (obtained by integration of the ascending aortic flow probe velocity signal) times the heart rate. Signals for 10-15 sinus beats were averaged for each data point. Post-premature beats and beats that varied $>10 \%$ in cycle length from the average heart rate were excluded from analyses.

Two approaches were applied for the measurement of the rate of isovolumic relaxation: the maximum rate of isovolumic pressure fall (16) obtained by high fidelity micromanometry ([-]dP/dt max), and $T$, the time constant of exponential left ventricular pressure fall after $\mathrm{dP} / \mathrm{dt} \max (17)$. The isovolumic relaxation period was defined as the time from $(-) \mathrm{dP} / \mathrm{dt}$ max until the time when left ventricular pressure fell to $5 \mathrm{mmHg}$ above the end-diastolic pressure of the following beat to exclude the potential effects of mitral valve opening upon the rate of left ventricular pressure decay.

Two methods were used to compute the time constant of left ventricular relaxation. First, we employed the method of Weiss et al. (17) originally proposed to compute $T$. If left ventricular pressure declined exponentially during this period then: $P(+)=P_{0} e^{-t / T}$. The natural logarithmic transformation of both sides of this equation yielded $\ln \mathrm{P}=-(1 / T) t+\ln \mathrm{P}_{0}$.

Therefore, $\ln \mathrm{P}$ is a linear function of time $(t)$ with a slope equal to $-1 / T$. To compute $T$, linear regression of the values of $\ln P$ vs. $t$ for the points obtained every $5 \mathrm{~ms}$ during the isovolumic period (Fig.
1) produced a slope that is the negative reciprocal of the time constant $(-1 / T)$. We have termed the value of $T$ as calculated from the logarithm of pressures $T_{1}$. The correlation of the plots of $\ln P$ vs. time was $\geq 0.98$ (mean $=0.99 \pm 0.01 \mathrm{SE}$ ) in all cases. However, this method has been shown to be sensitive to errors in the absolute value of pressure due to pericardial or pleural pressure changes $(18,19)$, and assumes the fully relaxed ventricle to have zero pressure. Therefore, we also derived $T$ using the method proposed by Raff et al. (20), who demonstrated that $\mathrm{dP} / \mathrm{dt}$ is a linear function of $\mathrm{P}$ with a slope of $-1 / T$, regardless of the magnitude of the base-line shift. Thus, we estimated $T$ by computing a linear regression of $\mathrm{dP} / \mathrm{dt}$ against $P$ using the points from the interval of isovolumic pressure fall. $T$ calculated from the first derivative of pressure has been called $T_{2}$. The linear regression of pressure and $\mathrm{dP} / \mathrm{dt}$ coordinates was also characterized by its pressure axis intercept (PB). This extrapolated base-line pressure calculated at $\mathrm{dP} / \mathrm{dt}=0$ represents the asymptote to which pressure would fall if dissipation of force continued infinitely (Fig. 2). Although the physiologic meaning of this measure is uncertain, it has been used by some as an index of the extent of ventricular relaxation in contrast to the rate of relaxation that is assessed by the time constant (21). The correlation of the plots of $\mathrm{dP} / \mathrm{dt}$ vs. $\mathrm{P}$ was $\geq 0.91$ in all cases (mean $=0.97 \pm 0.03$ ). Although polynominal curve fits have also been proposed (22) to assess the time constant of relaxation, these often demonstrate oscillatory behavior near the end points that results in spurious values of $T$ even though the fits may be the best in a statistical sense (23).

\section{Experimental protocols}

Group I $(n=7)$ intracoronary drug administration. In order to distinguish the direct myocardial effects of calcium channel blockade independent of peripheral vasodilation and reflex sympathetic stimulation, we observed the peak effects of intracoronary bolus doses of each drug. Diltiazem $(16 \pm 3 \mu \mathrm{g} / \mathrm{kg} \mathrm{SE})$ (Marion Laboratories, Inc., Kansas City, MO), verapamil $(10 \pm 2 \mu \mathrm{g} / \mathrm{kg}$ ) (Knoll Pharmaceutical Co., Whippany, $\mathrm{NJ})$ and, nifedipine $(1 \pm 0.1 \mu \mathrm{g} / \mathrm{kg})$ (Pfizer Chemical Div., Pfizer, Inc., Chicago, IL) were each administered on different days through the IC catheter over $10 \mathrm{~s}$, dissolved in $5 \mathrm{ml}$ of normal saline (diltiazem and verapamil) or $5 \mathrm{ml}$ of a light protected mixture of one part each of ethyl alcohol and polyethylene glycol plus seven parts of water (nifedipine), to dogs pretreated with intravenous atropine $0.1 \mathrm{mg} / \mathrm{kg}$. The drug vehicle alone produced no systemic or IC hemodynamic effects. The dose of atropine used has been shown to abolish the hypotensive effects of acetylcholine for $\mathbf{4 0} \mathrm{min}$; muscarinic blockade was employed to minimize the direct depressant effects of calcium entry blockade on the sinoatrial and atrioventricular nodes (5).

The dosages of the CEB were selected on the basis of preliminary studies in each animal of the relative amount of each drug required to produce equivalent reduction in circumflex regional segment gauge percentage of shortening in order to eliminate differences in relaxation produced by differing negative inotropic potencies among these agents (4). Smaller concentrations of each calcium blocker that did not affect regional myocardial shortening failed to produce any measurable effect on LV isovolumic relaxation. Peak effects of IC calcium blocker administration occurred 5-10 s after IC bolus injection and abated over the next $20 \mathrm{~min}$.

Group $2(n=12)$ systemic intravenous drug administration. In order to discern the integrated direct myocardial, peripheral arterial dilatation and reflex sympathetic effects (24) of the CEB upon isovolumic relaxation, we administered intravenous equihypotensive infusions of diltiazem, verapamil, and nifedipine $(63 \pm 9,57 \pm 5$, and $8 \pm 3 \mu \mathrm{g} / \mathrm{kg}$ per min, respectively) using a Harvard infusion pump on different days after $0.05 \mathrm{mg} / \mathrm{kg}$ atropine i.v. Identical infusions of the three CEB were subsequently given to six of these dogs after $2 \mathrm{mg} / \mathrm{kg}$ of intravenous propranolol. This dose of propranolol has been shown to abolish the effects of isoproterenol $(4-6 \mu \mathrm{g} / \mathrm{kg})$ on heart rate and $(+) \mathrm{dP} / \mathrm{dt} \max$ for $45 \mathrm{~min}$ (4). Resting steady state hemodynamic measurements were made before and at $10 \mathrm{~min}$ of systemic equihypotensive CEB infusion with the animal resting quietly in the sling.

Statistical analysis. Statistical treatment of the data was performed 
by one and two-way analyses of variance (ANOVA) for repeated measures and paired $t$ tests as appropriate (program BMDP2V). Where analysis of variance revealed a significant F-statistic, the NewmanKeuls multiple range test was employed to determine significant differences among group means (25). The results are summarized as the respective group mean $\pm 1 \mathrm{SE}$. The level of significance was chosen as $P \leq 0.05$.

\section{Results}

Group I-effects of intracoronary calcium entry blockade upon systemic hemodynamics and regional systolic function. Peak hemodynamic changes observed after IC diltiazem, verapamil, and nifedipine are recorded in Table I and Figs. 1-7. Both diltiazem and nifedipine produced modest but insignificant increases in heart rate (diltiazem $109 \pm 13-123 \pm 16$, nifedipine $124 \pm 14-126 \pm 9$, both $P=\mathrm{NS})$. By contrast, IC verapamil reduced heart rate from $127 \pm 13$ to $85 \pm 9(P<0.05)$ in these dogs. All three CEB produced declines in mean aortic pressure from $106 \pm 5$ to $88 \pm 5 \mathrm{mmHg}(P<0.04)$ for diltiazem; from $105 \pm 4$ to $89 \pm 6 \mathrm{mmHg}(P<0.02)$ for verapamil and from $102 \pm 6$ to $90 \pm 5 \mathrm{mmHg}(P<0.05)$ for nifedipine (Fig. 3). Left ventricular end-diastolic pressure was substantially increased by IC diltiazem from $8 \pm 2$ to $12 \pm 2 \mathrm{mmHg}(P<0.01)$, by verapamil from $5 \pm 1$ to $16 \pm 2 \mathrm{mmHg}(P<0.001)$, and by nifedipine from $5 \pm 1$ to $12 \pm 2 \mathrm{mmHg}(P<0.05)$. The increase in left ventricular end-diastolic pressure (LVEDP) after verapamil was greater $(P<0.005)$ than that observed after diltiazem or nifedipine. The first derivative of $\mathrm{LV}$ pressure $([+] \mathrm{dP} / \mathrm{dt}$ max) was reduced from $2,990 \pm 325$ to $2,470 \pm 640 \mathrm{mmHg} / \mathrm{s}$ $(\leq 0.01)$ by diltiazem, from $3,152 \pm 360$ to $2,367 \pm 242$ $\mathrm{mmHg} / \mathrm{s}(P \leq 0.02)$ by verapamil, and from $2,875 \pm 286$ to $2,445 \pm 288 \mathrm{mmHg} / \mathrm{s}(P \leq 0.03)$ by nifedipine (Fig. 4). The reduction in $\mathrm{dP} / \mathrm{dt}$ max did not differ significantly among the three CEB ( $P=$ NS by ANOVA). By experimental design, the doses of the CEB were selected to produce equivalent reductions in percentage of regional shortening of the $\mathrm{LV}$ base (Table I). Basal LV shortening was reduced from $14 \pm 2$ to $10 \pm 2 \%(P$ $<0.03)$ by diltiazem, from $14 \pm 2$ to $10 \pm 2 \%(P<0.05)$ by verapamil and from $12 \pm 2$ to $9 \pm 1 \%(P<0.02)$ by nifedipine (all $P=$ NS among drugs by ANOVA). Apical LV shortening was similarly reduced by circumflex intracoronary administration of all three CEB (Table I, Fig. 5).

Effects of IC calcium entry blockade upon isovolumic $L V$ relaxation. All three CEB produced equivalent and substantial declines in the indices of isovolumic relaxation (Table I and Figs. 1 and 2). Diltiazem reduced (-)dP/dt $\max$ from $2,636 \pm 197$ to $2,363 \pm 739 \mathrm{mmHg} / \mathrm{s}(P<0.01)$; verapamil from $2,450 \pm 255$ to $1,594 \pm 207 \mathrm{mmHg} / \mathrm{s}(P<0.02)$; and nifedipine from $2,449 \pm 233$ to $1,399 \pm 234 \mathrm{mmHg} / \mathrm{s}(P<0.03)$ (Fig. 6).

The effects of IC calcium entry blockade upon the time constant of $\mathrm{LV}$ isovolumic relaxation obtained by linear regression of the natural logarithm of pressure versus time $\left(T_{1}\right)$ are evident in Fig. 1 and Table I. Fig. 1 demonstrates the semilogarithmic plots of LV pressure versus time pre- and postdiltiazem, verapamil, and nifedipine in a single dog. In each case, the slope of the lines of best fit of these data points was reduced and the time constant $\left(T_{1}\right)$ prolonged compared to the respective control after IC CEB administration. Group data are displayed in Table I. $T_{1}$ was increased from $16 \pm 3$ to $31 \pm 11 \mathrm{~ms}(P<0.02)$ after diltiazem, from $16 \pm 2$ to $28 \pm 5 \mathrm{~ms}$ $(P<0.001)$ after verapamil, and from $16 \pm 3$ to $23 \pm 5 \mathrm{~ms}(P$ $<0.03$ ) after nifedipine ( $P=$ NS among drugs by ANOVA) (Fig. 7). $T_{2}$ was similarly and significantly prolonged by each of the calcium blockers (Table I, Fig. 2). $T_{2}$ was prolonged by $21 \%$ with diltiazem $(P<0.02)$, by $30 \%$ with verapamil ( $P$ $<0.05)$, and by $24 \%$ with nifedipine $(P<0.02)$. Although PB (at $0 \mathrm{dP} / \mathrm{dt}$ ) tended to rise with each CEB, the increase was only significant with verapamil $(-10 \pm 5 \pm 2 \mathrm{mmHg}, P<0.05)$.

Group 2-effects of equihypotensive intravenous infusions of calcium entry blockers upon systolic function pre- and postbeta blockade. Steady state hemodynamic changes produced during calcium blocker infusion are summarized in Table II. All three drugs evoked equivalent increases in heart rate (range $15-20 \%, P=$ NS among drugs by ANOVA). Heart rate was increased from $117 \pm 8$ to $137 \pm 9$ beats $/ \mathrm{min}(P<0.006)$ by diltiazem, from $125 \pm 8$ to $155 \pm 10$ beats $/ \min (P<0.003)$ by

Table I. Hemodynamic Effects of Intracoronary CEB (Group 1 Mean $\pm S E, n=7$ )

\begin{tabular}{|c|c|c|c|c|c|c|c|c|c|c|}
\hline Group & Heart rate & MAP & LVEDP & $\begin{array}{l}\% \Delta \mathrm{ll} \\
\text { base }\end{array}$ & $\begin{array}{l}\% \Delta \mathrm{l} \\
\text { apex }\end{array}$ & $(+) \mathrm{dP} / \mathrm{dt} \max$ & $(-) \mathrm{dP} / \mathrm{dt} \max$ & $T_{1}$ & $T_{2}$ & PB \\
\hline & beats/min & $m m H g$ & $m m H g$ & & & $m m H g / s$ & $m m H g / s$ & $m s$ & $m s$ & $\mathrm{mmHg}$ \\
\hline Control & $109 \pm 13$ & $106 \pm 5$ & $8 \pm 2$ & $14 \pm 2$ & $17 \pm 2$ & $2,990 \pm 325$ & $2,636 \pm 197$ & $16 \pm 3$ & $30 \pm 5$ & $-13 \pm 4$ \\
\hline \multicolumn{11}{|l|}{ Peak effect } \\
\hline diltiazem & $123 \pm 16$ & $88 \pm 5 \ddagger$ & $12 \pm 2 \ddagger$ & $10 \pm 2 \ddagger$ & $14 \pm 3 \ddagger$ & $2,470 \pm 640 \ddagger$ & $2,363 \pm 739 \ddagger$ & $31 \pm 11 \ddagger$ & $38 \pm 5 \ddagger$ & $-2 \pm 5$ \\
\hline \multicolumn{11}{|l|}{ Verapamil } \\
\hline Control & $127 \pm 13$ & $105 \pm 4$ & $5 \pm 1$ & $14 \pm 2$ & $17 \pm 3$ & $3,152 \pm 360$ & $2,450 \pm 255$ & $16 \pm 2$ & $26 \pm 3$ & $-10 \pm 3$ \\
\hline \multicolumn{11}{|l|}{ Peak effect } \\
\hline verapamil & $85 \pm 9 \ddagger \S$ & $89 \pm 6 \ddagger$ & $16 \pm 2 \ddagger \S$ & $10 \pm 2 \ddagger$ & $13 \pm 2 \ddagger$ & $2,367 \pm 242 \ddagger$ & $1,594 \pm 207 \ddagger$ & $28 \pm 5 \ddagger$ & $37 \pm 5 \ddagger$ & $5 \pm 2 \ddagger \S$ \\
\hline \multicolumn{11}{|l|}{ Nifedipine } \\
\hline Control & $124 \pm 14$ & $102 \pm 6$ & $5 \pm 1$ & $12 \pm 2$ & $17 \pm 3$ & $2,875 \pm 286$ & $2,499 \pm 233$ & $16 \pm 3$ & $28 \pm 3$ & $-15 \pm 10$ \\
\hline \multicolumn{11}{|l|}{ Peak effect } \\
\hline nifedipine & $126 \pm 9$ & $90 \pm 5 \ddagger$ & $12 \pm 2 \ddagger$ & $9 \pm 1 \ddagger$ & $15 \pm 2$ & $2,445 \pm 288 \ddagger$ & $1,399 \pm 234 \ddagger$ & $23 \pm 5 \ddagger$ & $37 \pm 4 \ddagger$ & $3 \pm 5$ \\
\hline
\end{tabular}

MAP, mean aortic pressure; $\% \Delta \mathrm{l}$ base and apex, percentage of shortening of the regional segment gauge pairs in the circumflex and anterior descending coronary artery regions, respectively; $\mathrm{PB}$, pressure baseline. ${ }^{*}$ Group 1 mean $\pm \mathrm{SE}, n=7$. $\ddagger P \leq 0.05$ vs. respective control by paired $t$ test. $\S P \leq 0.05$ vs. nifedipine and diltiazem by ANOVA. 
Table II. Hemodynamic Effects of Equihypotensive Intravenous Infusions of CEB Pre-and Postbeta Blockade*

\begin{tabular}{|c|c|c|c|c|c|c|c|c|c|c|c|}
\hline Group & $\begin{array}{l}\text { Heart } \\
\text { rate }\end{array}$ & MAP & LVEDP & LVEDD & $\% \Delta \mathrm{D}$ & CO & $(+) \mathrm{dP} / \mathrm{dt} \max$ & $(-) \mathrm{dP} / \mathrm{dt} \max$ & $T_{1}$ & $T_{2}$ & PB \\
\hline & beat/min & $m m H g$ & $m m H g$ & $m m$ & & liter/min & $m m H g / s$ & $m m H g / s$ & $m s$ & $m s$ & $m m H g$ \\
\hline \multicolumn{12}{|l|}{$\begin{array}{l}\text { Dilitiazem } \\
\qquad(n=12)\end{array}$} \\
\hline Control & $117 \pm 8$ & $99 \pm 4$ & $9 \pm 2$ & $44 \pm 2$ & $17 \pm 1$ & $1.96 \pm 0.27$ & $2,690 \pm 253$ & $2,321 \pm 147$ & $16 \pm 2$ & $39 \pm 6$ & $-11 \pm 5$ \\
\hline Dilitiazem & $137 \pm 9 \ddagger$ & $89 \pm 3 \ddagger$ & $8 \pm 1$ & $44 \pm 2$ & $19 \pm 1$ & $2.25 \pm 0.37$ & $2,740 \pm 242$ & $2,232 \pm 163$ & $15 \pm 1$ & $37 \pm 5$ & $-10 \pm 4$ \\
\hline $\begin{array}{l}\text { Beta blockade } \\
\quad(n=6) \\
\text { Beta blockade }\end{array}$ & $116 \pm 7$ & $101 \pm 4$ & $9 \pm 4$ & $40 \pm 2$ & $16 \pm 2$ & $1.93 \pm 0.31$ & $2,264 \pm 108 \ddagger$ & $2,258 \pm 137$ & $17 \pm 2$ & $43 \pm 2$ & $-8 \pm 2$ \\
\hline + dilitiazem & $130 \pm 6 \ddagger$ & $96 \pm 4$ & $9 \pm 3$ & $40 \pm 3$ & $16 \pm 2 \S$ & $2.20 \pm 0.25 \ddagger$ & $2,245 \pm 123 \S$ & $2,208 \pm 112$ & $17 \pm 2$ & $40 \pm 3$ & $-9 \pm 3$ \\
\hline \multicolumn{12}{|l|}{$\begin{array}{l}\text { Verapamil } \\
\qquad(n=12)\end{array}$} \\
\hline Control & $125 \pm 8$ & $98 \pm 5$ & $10 \pm 2$ & $44 \pm 2$ & $17 \pm 2$ & $2.05 \pm 0.36$ & $2,781 \pm 296$ & $2,278 \pm 183$ & $15 \pm 2$ & $38 \pm 6$ & $-13 \pm 6$ \\
\hline $\begin{array}{l}\text { Verapamil } \\
\text { Beta blockade }\end{array}$ & $155 \pm 10 \ddagger$ & $90 \pm 4 \ddagger$ & $10 \pm 2$ & $42 \pm 3$ & $17 \pm 2^{\prime \prime}$ & $1.85 \pm 0.31^{\prime \prime}$ & $2,599 \pm 286^{\prime \prime}$ & $2,098 \pm 184$ & $15 \pm 2$ & $37 \pm 4$ & $-13 \pm 7$ \\
\hline $\begin{array}{l}(n=6) \\
\text { Beta blockade } \\
\text { plus }\end{array}$ & $120 \pm 6$ & $95 \pm 4$ & $9 \pm 4$ & $39 \pm 2$ & $15 \pm 2$ & $2.05 \pm 0.29$ & $2,130 \pm 87 \ddagger$ & $1,986 \pm 71$ & $17 \pm 2$ & $40 \pm 1$ & $-12 \pm 7$ \\
\hline verapamil & $135 \pm 8 \neq \S$ & $89 \pm 4$ & $11 \pm 2$ & $39 \pm 3$ & $14 \pm 2 \S^{\prime \prime}$ & $2.39 \pm 0.22$ & $1,775 \pm 170 \neq \S^{\prime \prime}$ & $1,788 \pm 101 \neq \S^{\prime \prime}$ & $20 \pm 1 \S^{\prime \prime}$ & $44 \pm 3 \S^{\prime \prime}$ & $-13 \pm 5$ \\
\hline \multicolumn{12}{|l|}{$\begin{array}{l}\text { Nifedipine } \\
\qquad(n=12)\end{array}$} \\
\hline Control & $115 \pm 9$ & $99 \pm 4$ & $11 \pm 2$ & $44 \pm 2$ & $18 \pm 2$ & $1.96 \pm 0.34$ & $2,713 \pm 179$ & $2,410 \pm 183$ & $17 \pm 1$ & $40 \pm 6$ & $-11 \pm 4$ \\
\hline $\begin{array}{l}\text { Nifedipine } \\
\text { Beta blockade }\end{array}$ & $146 \pm 10 \ddagger$ & $90 \pm 4 \ddagger$ & $10 \pm 2$ & $44 \pm 2$ & $20 \pm 2$ & $2.60 \pm 0.50 \ddagger$ & $2,934 \pm 260$ & $2,349 \pm 198$ & $14 \pm 2 \ddagger$ & $32 \pm 2 \ddagger$ & $-13 \pm 6$ \\
\hline $\begin{array}{c}(n=6) \\
\text { Beta blockade }\end{array}$ & $114 \pm 6$ & $94 \pm 5$ & $7 \pm 2$ & $39 \pm 2$ & $16 \pm 2$ & $1.97 \pm 0.3$ & $2,145 \pm 104 \ddagger$ & $2,232 \pm 121$ & $16 \pm 3$ & $40 \pm 3$ & $-19 \pm 5$ \\
\hline+ nifedipine & $133 \pm 6 \neq \S$ & $94 \pm 5$ & $8 \pm 2$ & $40 \pm 1$ & $16 \pm 2 \S$ & $2.22 \pm 0.25 \ddagger$ & $2,206 \pm 116 \S$ & $2,361 \pm 133$ & $16 \pm 1$ & $41 \pm 3$ & $-14 \pm 3$ \\
\hline
\end{tabular}

LVEDD, LV end-diastolic transverse dimension; LVEDP, left ventricular end-diastolic pressure; MAP, mean aortic pressure; $\% \triangle D$, percentage of shortening of the LV transverse dimension; $\mathrm{CO}$, cardiac output; $\mathrm{PB}$, pressure baseline. ${ }^{*}$ Group 2 mean $\pm \mathrm{SE}$. $\ddagger P<0.05$ vs. respective control. $\S P<0.05$ vs. calcium entry blocker alone. " $P<0.05$ vs. nifedipine, dilitiazem.

verapamil, and from $115 \pm 9$ to $146 \pm 10$ beats/min $(P<0.004)$ by nifedipine. Post-beta blockade $(n=6)$ similar directional changes in heart rate were observed with each drug; however, the increments were significantly attenuated compared with those observed with calcium entry blockade alone (Table II, $P$ $<0.05$ for verapamil and nifedipine). Intravenous diltiazem reduced mean aortic pressure from $99 \pm 4$ to $89 \pm 3 \mathrm{mmHg}(P$ $<0.001)$, verapamil from $98 \pm 5$ to $90 \pm 4 \mathrm{mmHg}(P<0.02)$, and nifedipine from $99 \pm 4$ to $90 \pm 4 \mathrm{mmHg}(P<0.02)$. Postbeta blockade there was no significant decline in systemic arterial pressure with any of the calcium blockers despite use of the same dose that was employed before propranolol (Table II).

Neither LV end-diastolic pressure nor transverse diameter were significantly altered with any of the calcium blockers preor post-beta adrenergic blockade. Percentage of shortening of the LV minor diameter signal $(\% \Delta \mathrm{D})$ increased from $17 \pm 1$ to $19 \pm 1(P=\mathrm{NS})$ with diltiazem, from 18 to $20 \%(P=\mathrm{NS})$ with nifedipine, and remained unchanged at $17 \pm 2 \%$ with verapamil $(P<0.05$ vs. diltiazem, $P<0.008$ vs. nifedipine). LV percentage of shortening with each drug postpropranolol was significantly reduced when compared with percentage of shortening with the respective calcium blocker alone (Table II). Extent of LV shortening was significantly less after the combination of propranolol and verapamil $(14 \pm 2 \%)$ than after beta blockade plus either diltiazem or nifedipine (each $16 \pm 2, P<0.03$ vs. verapamil). Cardiac output was unchanged from control after diltiazem $(1.96 \pm 0.27-2.25 \pm 0.37 \mathrm{liter} / \mathrm{min}, P=\mathrm{NS})$ or verapamil $(2.05 \pm 0.36-1.85 \pm 0.31 \mathrm{liter} / \mathrm{min}, P=\mathrm{NS})$ and was increased by the equihypotensive infusion of nifedipine (1.95 $\pm 0.34-2.60 \pm 0.50$ liter/min, $P<0.04)$. Post-beta blockade cardiac output was significantly increased by diltiazem (1.93 $\pm 0.31-2.20 \pm 0.25 \mathrm{liter} / \mathrm{min}, P<0.02)$ and nifedipine (1.97 $\pm 0.3-2.22 \pm 0.25$ liter $/ \mathrm{min}, P<0.04)$, but unchanged by verapamil $(2.05 \pm 0.29-2.39 \pm 0.22, P=\mathrm{NS})$.

In the doses used in this investigation, no significant change from control in (+)dP/dt max was observed during intravenous calcium blocker administration. However, the group mean for $\mathrm{dP} / \mathrm{dt}$ max during verapamil administration $(2,599 \pm 286$ $\mathrm{mmHg} / \mathrm{s}$ ) was significantly less than that observed during either diltiazem $(2,740 \pm 242 \mathrm{mmHg} / \mathrm{s}, \quad P<0.05)$ or nifedipine $(2,934 \pm 260 \mathrm{mmHg}, P<0.02)$. Similarly, post-beta blockade, the group mean for $\mathrm{dP} / \mathrm{dt}$ max with verapamil $(1,775 \pm 170$ $\mathrm{mmHg} / \mathrm{s}$ ) was significantly depressed relative to diltiazem $(2,245 \pm 123 \mathrm{mmHg} / \mathrm{s}, P<0.02)$ and nifedipine $(2,206 \pm 116$ $\mathrm{mmHg} / \mathrm{s}, P<0.02)$. Group means for $(+) \mathrm{dP} / \mathrm{dt}$ max for each of the combinations of beta blockade plus diltiazem, verapamil, and nifedipine were significantly less than the group means observed during calcium entry blockade alone, each $P<0.05$.

Effects of intravenous calcium entry blockade upon isovolumic $L V$ relaxation. In contrast to the significant reductions in $(-) \mathrm{dP} / \mathrm{dt} \max$ observed in response to intracoronary diltiazem, verapamil, and nifedipine (Table I), intravenous equihypotensive calcium blocker administration produced no change in the rate of isovolumic LV pressure fall (Table II). However, post-beta blockade verapamil significantly reduced $(-) \mathrm{dP} / \mathrm{dt}$ $\max (1,986 \pm 71-1,788 \pm 101 \mathrm{mmHg} / \mathrm{s}, P<0.04)$. No significant change in $(-) \mathrm{dP} / \mathrm{dt}$ max was observed postpranolol with either 

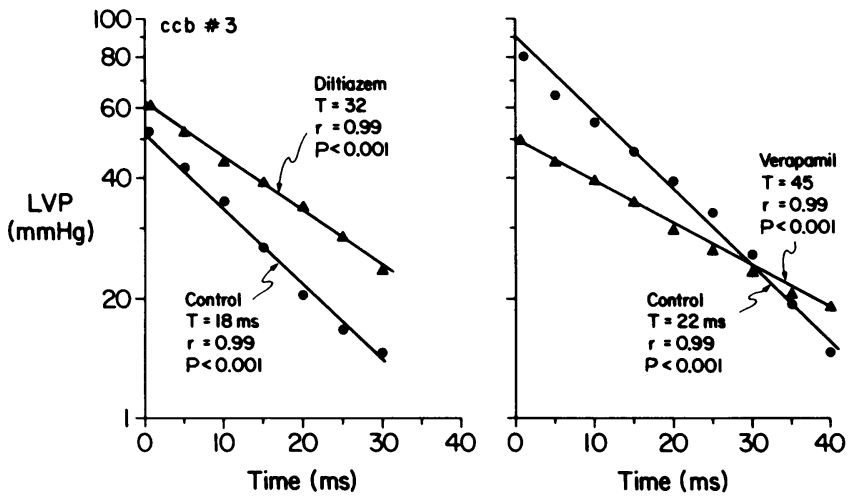

diltiazem $(2,258 \pm 137-2,208 \pm 112, \quad P=\mathrm{NS})$ or nifedipine $(2,232 \pm 121-2,361 \pm 133, P=\mathrm{NS})$.

$T_{1}$, the time constant of $\mathrm{LV}$ relaxation was not altered by either intravenous diltiazem $(16 \pm 2-15 \pm 1 \mathrm{~ms}, P=\mathrm{NS})$ or verapamil (15 $\pm 2-15 \pm 2 \mathrm{~ms})$. However, intravenous nifedipine significantly reduced $T_{1}(17 \pm 1-14 \pm 2 \mathrm{~ms}, P<0.01)$. This effect was abolished after beta adrenergic blockade (16 $\pm 3-16 \pm 1 \mathrm{~ms})$. Postpropranolol, verapamil significantly prolonged $T_{1}$ from $17 \pm 2$ to $20 \pm 1 \mathrm{~ms}(P<0.05)$. Similar directional changes in $T_{2}$ were observed for each of the calcium blockers pre- and post-beta blockade. The $\mathrm{PB}$ at $0 \mathrm{dP} / \mathrm{dt}$ was not significantly changed from control by intravenous calcium entry blockade before or during propranolol (Table II).

\section{Discussion}

The results of this investigation suggest that calcium entry blockade produces divergent effects upon the dissipation of left ventricular force that are dependent upon the mode of drug administration. These agents directly impair relaxation in normal ventricular myocardium. However, this action may be attenuated or even reversed during systemic administration because of the concomitant effects of calcium blockade upon ventricular loading conditions and reflex sympathetic stimulation. We used the intracoronary route to observe direct drug effects independent of reflex changes and the intravenous route to compare the effects of the three widely used calcium blockers on overall LV performance in conscious dogs with reflexes intact. The IC bolus injection of diltiazem, verapamil, and nifedipine in dosages that produced equivalent reductions in the extent of $\mathrm{LV}$ chamber shortening and rate of pressure development (hereafter referred to as equidepressant) evoked significant declines in the rate of isovolumic relaxation as assessed by $(-) \mathrm{dP} / \mathrm{dt} \max$ and $T$, the time constant of $\mathrm{LV}$ pressure decay (Table I, Figs. 1 and 2). Lesser amounts of each of these agents that were without effect upon systolic LV performance were also without discernable effect upon diastolic relaxation. By contrast, the intravenous infusion of the CEB pre-beta blockade in dosages that reduced arterial pressure equally (hereafter called equihypotensive) either substantially augmented ventricular relaxation (nifedipine) or produced no significant change in $(-) \mathrm{dP} / \mathrm{dt}$ max or either measure of $T$ (diltiazem and verapamil, Table II). When a subgroup of these dogs $(n=6$, Table II) were given identical intravenous dosages of each of the CEB after nonselective beta adrenergic blockade with propranolol, the improvement in the rate of LV relaxation

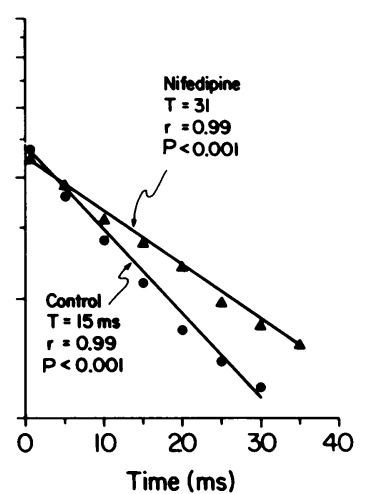

Figure 1. Representative semilogarithmic plots of LV pressure vs. time preand post-IC calcium entry blocker administration in a single dog. The slopes of the lines of best fit of these data points were reduced and the time constants $\left(T_{1}\right)$ of isovolumic $\mathrm{LV}$ relaxation were prolonged in each case compared to the respective control.

produced by nifedipine was prevented and relaxation was significantly impaired by verapamil.

These results may be explained by an analysis of the effects of IC and intravenous calcium entry blockade upon the fundamental determinants of relaxation in cardiac muscle (26). Decay of ventricular pressure is governed by the continuous interplay of the sensitivity of the contractile system to the prevailing load and by inactivation, the energy-dependent process whereby the calcium ion, removed from troponin, is sequestered in the sarcoplasmic reticulum against its concentration gradient. More recently the potential importance of the nonuniform distribution of load and inactivation in space and time has also been recognized (27). The dosages of the CEB employed for IC administration produced equivalent effects upon the rate of $\mathrm{LV}$ pressure development, extent of $\mathrm{LV}$ muscle shortening, and loading conditions. The substantial reduction in pressure development and muscle shortening produced by calcium entry blockade may retard $L V$ relaxation by diminishing external $\mathrm{LV}$ chamber restoring forces (i.e., the potential energy stored during systolic deformation). All three agents produced significant increases in $\mathrm{LV}$ end-diastolic pressure. Raff and colleagues (20) have demonstrated that increases in preload may impair ventricular relaxation independently of other factors. Although heart rate alterations alone have been

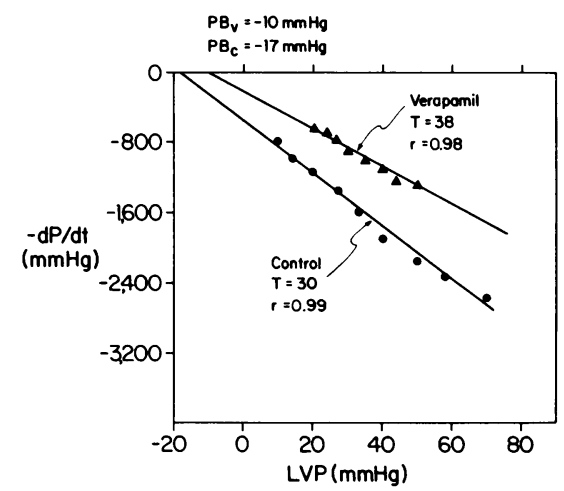

Figure 2. Negative $\mathrm{dP} / \mathrm{dt}$ and left ventricular pressure (LVP) data pre- and post-IC verapamil in the same dog as in Fig. 1. The time constant ( $T_{2}$, milliseconds) of relaxation is the negative reciprocal of the slope of the linear regression of $\mathrm{dP} / \mathrm{dt}$ and pressure coordinates during isovolumic relaxation. The regression line is extended to the pressure axis intercept. The time constant $(T=37)$ and the PB $\left(\mathrm{PB}_{\mathrm{v}}=-10\right)$ were increased with IC verapamil compared to control $\left(T=30, \mathrm{~PB}_{\mathrm{c}}=-17\right)$. 


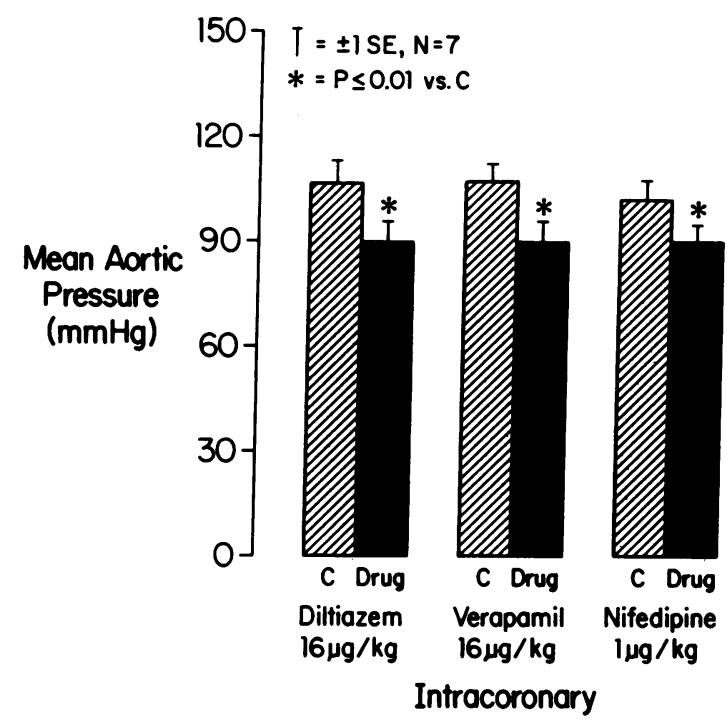

Figure 3. Relative effects of IC calcium entry blockade (group 1) upon mean aortic pressure. Each drug produced modest but significant reductions in arterial pressure of $<10 \%$ from respective controls (C).

shown to have an inverse effect upon the duration of the time constant in the awake dog (28), the magnitude of change required is considerably in excess of that which we observed with verapamil. Neither nifedipine nor diltiazem affected heart rate in these atropinized dogs, and yet each drug impaired LV relaxation.

Mechanical dyssynchrony may also impair global ventricular pressure decay if delayed activation produces late regional contraction of a myocardial segment during isovolumic relaxation (27). Although we cannot entirely exclude temporal inhomogeneity of ventricular activation/deactivation as a contributory determinant of the impaired relaxation observed with circumflex intracoronary calcium entry blockade, such an effect seems unlikely since $(a)$ minimum regional segment length always occurred before peak $(-) \mathrm{dP} / \mathrm{dt}$ during calcium

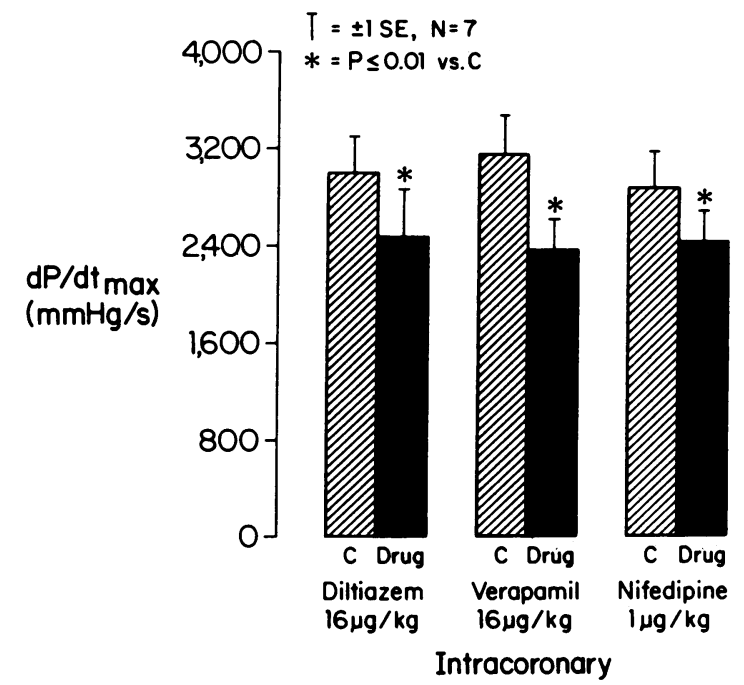

Figure 4. IC calcium entry blockers produced equivalent reductions in the rate of $\mathrm{LV}$ pressure development in the doses used.

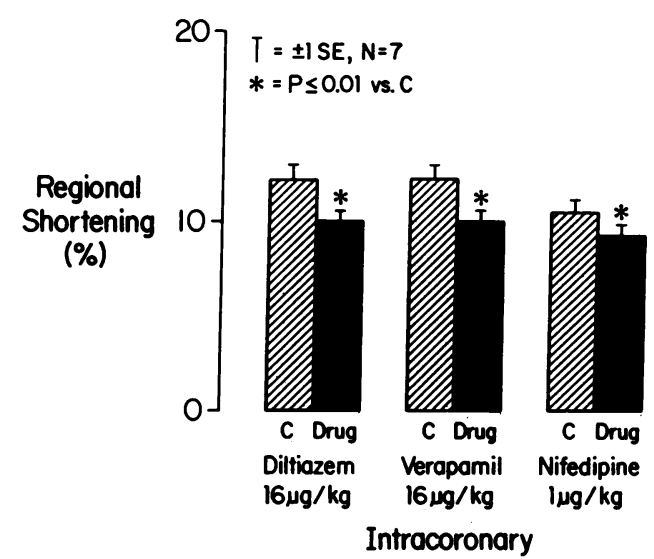

Figure 5. Each of the CEB produced significant reductions from their respective controls $(C)$ in percentage of regional shortening of the basal LV. The decrease in regional shortening was equivalent among the agents by experimental design. Similar decreases in shortening were observed in the apical LV region (see Table I).

blockade despite diminished extent of shortening; $(b)$ segment lengths were unchanged during the period of isovolumic relaxation; and (c) both basal and apical LV segments evidenced reduced shortening during drug administration. These results differ somewhat from the data of Serruys and coworkers (29) who observed that minimal separation of epicardial regional marker pairs occurred after end-systole (as determined by aortic incisura pressure) subsequent to intrabypass injection of $100 \mu \mathrm{g}$ of nifedipine in patients post-coronary revascularization. These differences may be explained by the relatively greater amount of myocardium supplied by the circumflex coronary artery and the abundance of native collaterals observed in the dog in contrast to man (30). Thus we observed diminished regional shortening of the LV base and apex in the dog after IC calcium entry blockers, while Serruys et al. detected no change in the velocity or extent of shortening of independently perfused regions after intrabypass graft injection of nifedipine in patients.

The impairment of left ventricular relaxation observed after IC calcium entry blockade and the tight coupling between depression of muscle contraction and relaxation appears consonant with the known effects of altered transcellular calcium flux in myocardial cells, in isolated papillary muscle and in the intact heart. Katz et al. (31) demonstrated that a decrease in cytosolic $\mathrm{Ca}^{++}$may increase the affinity of $\mathrm{Ca}^{++}$-troponin binding. It has also been shown that cytosolic ionized calcium is a necessary substrate for the sarcoplasmic membrane $\mathrm{Ca}^{++}$. ATPase believed responsible for calcium sequestration and inactivation of contraction (32). Thus, the reduction in transmembrane calcium flux produced by these drugs might be expected to diminish inactivation-dependent relaxation paripassu with a reduction in contraction, since there is little evidence for any direct intracellular action of the available CEB (33). Parmley and Sonnenblick (34) reported an increase in the time to half relaxation of isometric twitch contractions but no effect on the time constant of exponential force decline in isotonic afterloaded contractions at calcium concentrations of 2.5-7.5 mM. By contrast, Karliner and colleagues (28) actually observed shortening of the time constant of relaxation after intravenous calcium chloride administration in a dose 


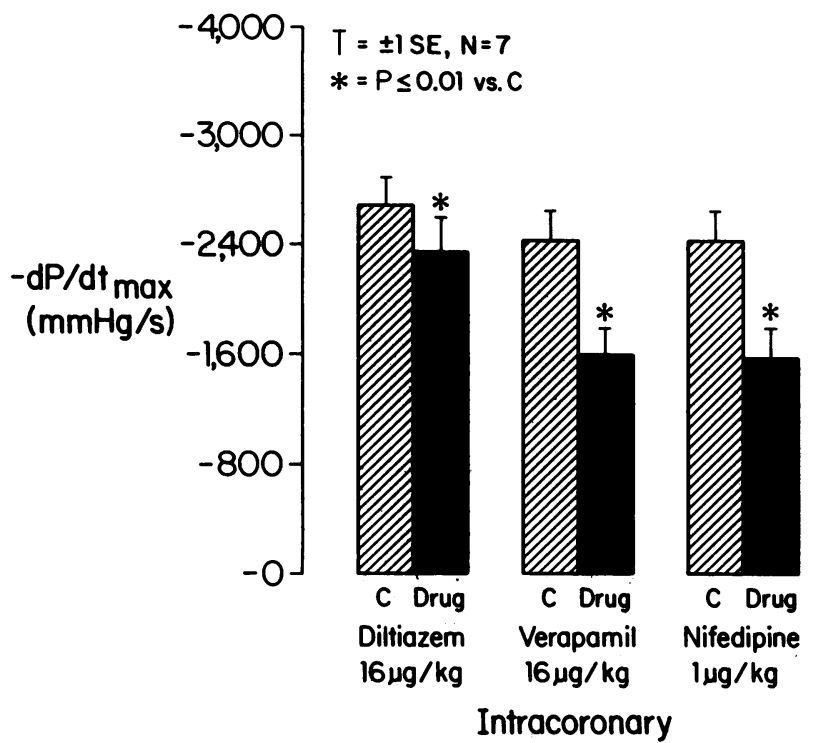

Figure 6. IC calcium entry blockers each significantly reduced (-) $\mathrm{dP} / \mathrm{dt} \max$.

sufficient to augment $\mathrm{LV} \mathrm{dP} / \mathrm{dt}$ max by $20 \%(2-9 \mathrm{mg} / \mathrm{kg})$ in the conscious dog. The variance between these studies may be explained by the differences in the concentration of extracellular calcium attained and by the differences in the distribution of load during isotonic papillary muscle and auxotonic ventricular chamber shortening coupled with a potentially greater role for external restoring forces as a determinant of relaxation in the ejecting heart (35). Importantly, neither study indicates that changes in transcellular calcium flux may affect ventricular relaxation of normal cardiac muscle independent of alterations in loading.

IC calcium entry blockade with all three drugs in equidepressant dosages produced substantial prolongations of ventricular relaxation as assessed by $(-) \mathrm{dP} / \mathrm{dt}$ and $T$, the time constant of LV relaxations (Table I, Figs. 1 and 2). By contrast,

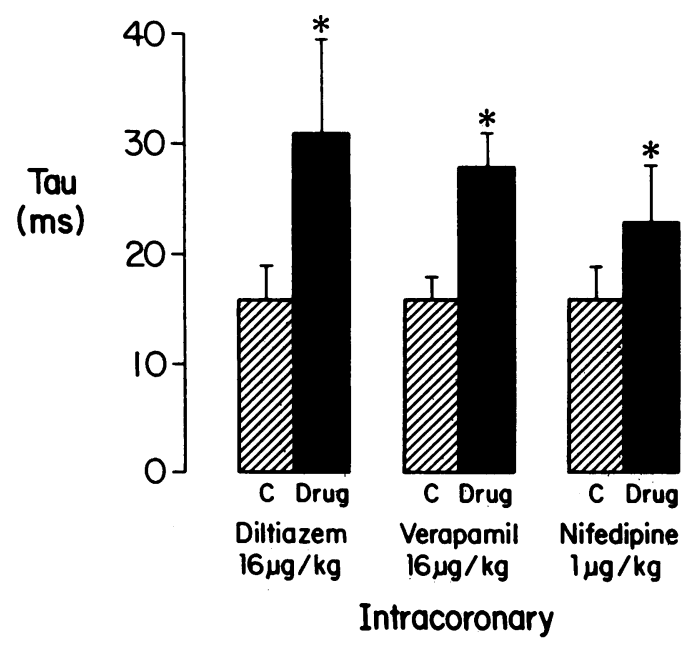

Figure 7. The effects of IC calcium entry blockade upon the time constant $\left(T_{1}\right)$ of $\mathrm{LV}$ relaxation are shown. Each calcium blocker significantly and equivalently prolonged $T_{1}$. Similar directional changes were observed in $T_{2}$ (see Table I). intravenous equihypotensive infusions of the CEB evoked either a significant decrease in $T_{1}$ and $T_{2}$ (nifedipine) or no significant change in this measure of relaxation (diltiazem and verapamil) (Table II). The small and statistically insignificant reductions in $(-) \mathrm{dP} / \mathrm{dt} \max$ (Table II) after all three drugs may be explained by the well known sensitivity of the first derivative of $\mathrm{LV}$ pressure fall to the level of systemic arterial pressure (16). The relative improvement in ventricular relaxation observed after intravenous as compared with IC calcium blockade may be explained by the preponderance of reflex and peripheral changes over direct myocardial effects during systemic administration. The reduction in systemic arterial pressure produced during calcium blocker infusions was associated with modest but significant increases in heart rate secondary to baroreceptor-mediated sympathetic stimulation and vagal withdrawal $(4,5)$. Nonselective beta adrenergic blockade attenuated but did not reverse the increase in heart rate during calcium blockade and was associated with either no improvement (nifedipine and diltiazem) or a decrease (verapamil) in isovolumic relaxation. The differential effects of systemic calcium entry blockade upon the rate of $\mathrm{LV}$ pressure decay pre- and postpropranolol suggests an important role for the sympathetic nervous system in modifying or reversing the direct effects of these compounds on the relaxation process. Sympathetic agonists have been demonstrated to enhance relaxation in both isometrically and isotonically contracting cardiac muscle $(24,34)$ in the isolated heart $(17)$ and in conscious animals (28). Although $\mathrm{dP} / \mathrm{dt} \max$ was not reflexly increased during drug infusion, catecholamines, unlike calcium, have been shown to improve ventricular relaxation independent of their effects upon load. For example, in isolated rat hearts calcium produced symmetrical changes in the velocity of contraction and relaxation (36), whereas isoproterenol increased the velocity of relaxation more than the velocity of contraction.

Extent of shortening and rate of pressure development were reduced with each of the CEB plus propranolol compared with calcium blockade alone (Table II), and may have contributed to the unfavorable changes in relaxation observed with nifedipine and verapamil post-beta blockade (Table II). Other factors seem less likely to explain the improvement in relaxation observed during systemic nifedipine. Ventricular preload (LV dimension and pressure) was not altered by nifedipine despite the decline in aortic pressure. Although increases in heart rate produced by atrial pacing alone may produce a moderate reduction in the time constant of $L V$ relaxation in awake dogs (28), the increment in heart rate produced by pacing $(+50 \%)$ necessary to produce such changes was considerably greater than the heart rate increment during nifedipine in this study $(+27 \%)$.

Several recent clinical investigations have emphasized the presence of abnormalities of ventricular filling in patients with hypertrophic cardiomyopathy $(7,9)$ or coronary artery disease (8) using radionuclide angiographic or echocardiographic techniques. Chronic oral verapamil administration produced clinical improvement in both patient groups (7) associated with favorable alterations in diastolic-filling indices. However, without quantitative left ventricular volume measurements and analysis of simultaneous pressure-volume relations, the abnormalities of left ventricular diastolic filling and the improved filling rate with verapamil can not be attributed directly to changes in diastolic chamber stiffness. Without measurement of the precise 
course of relaxation and filling, the reduced time to peak filling could be ascribed to a shortening of isovolumic relaxation time, a shortening of the rapid-filling period, or both of these phases of diastole. Paulus and colleagues (9) did observe a decrease in the time constant of relaxation with nifedipine during cardiac catheterization in patients with hypertrophic cardiomyopathy. However, a similar reduction in $T$ was observed after equihypotensive nitroprusside. The results of this study and our data suggest that favorable alterations in ventricular loading and reflex sympathetic stimulation produced by calcium entry blockade may importantly affect these observed alterations in diastolic function. Although the current investigation involved acute administration of $C E B$, we have observed significant elevations in circulating catecholamines at rest and during exercise with chronic oral diltiazem therapy in patients with coronary artery disease (37).

It is important to emphasize that our observations regarding the depressant effect of calcium entry blockade upon ventricular relaxation were made in the normal heart. Pathologic intracellular calcium overload produced by elevating external calcium concentration from 0.9 to $8 \mathrm{mM}$ in cultured chick embryo ventricular cells (38) and by ischemic myocardial contracture in the isolated rabbit heart (39) has been associated with impaired velocity of relaxation and elevated end diastolic pressures, respectively. Preadministration of verapamil (2 $\left.\times 10^{-8} \mathrm{M}\right)$ improved relaxation of the isolated calcium overloaded cell and nifedipine $\left(1 \times 10^{-7} \mathrm{M}\right)$ prevented the abnormal elevation of diastolic pressure in the isolated ischemic heart. In the clinical setting, pacing-induced angina pectoris in patients with coronary artery disease is associated with impaired ventricular relaxation and elevated end diastolic pressures (40). This impairment of relaxation during acute ischemia has been prevented using nifedipine (41). In patients, the mechanisms of the beneficial effects of calcium entry blockade upon LV relaxation during acute ischemia remain incompletely defined and are probably multifactorial. Favorable alterations in transmembrane calcium flux, ventricular loading conditions, the synchrony of contraction and relaxation, myocardial energy substrate availability, and utilization and reflex sympathetic stimulation may all contribute to the improvement in early and late diastolic function produced by these drugs.

In summary, we have demonstrated in the normal awake dog that equidepressant amounts of the available calcium entry blockers directly and equivalently impair isovolumic LV relaxation. This effect is closely linked to the alterations in systolic function produced by calcium blockade. The impairment of LV relaxation is attenuated or reversed by reflex sympathetic stimulation and favorable loading conditions during systemic administration. Further studies that control for these variables are needed to clarify the direct mechanical effects of reduced transmembrane calcium flux upon hypertrophied and ischemic myocardium.

\section{Acknowledgments}

We express our gratitude to Christopher Neal, Danny Ecobedo, and Donald Watkins for their technical support and to Debbie Palmer for her secretarial assistance.

This paper was supported in part by grants from the American Heart Association, Texas Affiliate, Inc., a Veteran's Administration Merit Grant, and grant HL 33579 from the National Heart Lung and Blood Institute.

\section{References}

1. Ellrodt, G., C. Y. C. Chew, and B. N. Sing. 1980. Therapeutic implications of slow channel blockade in cardiocirculatory disorders. Circulation. 62:669-679.

2. Henry, P. D. 1980. Comparative pharmacology of calcium antagonists: nifedipine, verapamil and diltiazem. Am. J. Cardiol. 46: 1047-1058.

3. Newman, R. K., V. S. Bishop, D. F. Peterson, E. J. Leroux, and L. D. Horowitz. 1977. Effect of verapamil on left ventricular performance in conscious dogs. J. Pharmacol. Exp. Ther. 201:723-730.

4. Walsh, R. A., F. R. Badke, and R. A. O'Rourke. 1981. Differential effects of systemic and intracoronary calcium channel blocking agents on global and regional left ventricular function in conscious dogs. Am. Heart J. 102:341-350.

5. Nakaya, H., A. Schwartz, and R. W. Millard. 1983. Reflex chronotropic and inotropic effects of calcium channel blocking agents in conscious dogs. Circ. Res. 52:302-311.

6. Porter, C. B., R. A. Walsh, F. R. Badke, and R. A. O'Rourke. 1983. Differential effects of diltiazem and nitroprusside on left ventricular function in experimental chronic volume overload. Circulation. 68: 685-692.

7. Bonow, R. O., D. R. Rosing, S. L. Bacharach, M. V. Green, K. M. Kent, L. C. Lipson, B. J. Maron, M. B. Leon, and S. E. Epstein. 1981. The effects of verapamil on left ventricular systolic function and diastolic filling in patients with hypertrophic cardiomyopathy.

8. Bonow, R. O., M. B. Leon, D. R. Rosing, K. M. Kent, L. C. Lipson, S. L. Bacharach, M. V. Green, and S. E. Epstein. 1981. The effects of verapamil and propranolol on left ventricular systolic function and diastolic filling in patients with coronary artery disease: radionuclide angiographic studies at rest and during exercise. Circulation. 65:13371350.

9. Paulus, W. J., B. H. Lorell, W. E. Craig, J. Winne, J. P. Murgo, and W. Grossman. 1983. Comparison of the effects of nitroprusside and nifedipine on diastolic properties in patients with hypertrophic cardiomyopathy: altered left ventricular loading or improved muscle inactivation? J.A.C.C. 2:879-886.

9a. Lorell, B. H., Z. Turi, and W. Grossman. 1981. Modification of left ventricular response to pacing tachycardia by nifedipine in patients with coronary artery disease. Am. J. Med. 71:667-675.

10. Brutsaert, D. L., P. R. Hausmans, and M. A. Goethals. 1980. Dual control of relaxation: its role in the ventricular function in the mammalian heart. Circ. Res. 47:637-652.

11. Walsh, R. A., and L. D. Horowitz. 1979. Adverse hemodynamic effects of intravenous disopyramide compared with quinidine in conscious dogs. Circulation. 60:1053-1060.

12. Franklin, D. L., W. Kemper, R. Patrick, and D. McKown. 1973. Technique for continuous measurement of regional myocardial segment dimensions in chronic animal preparations. Fed. Proc. 32: 343-347.

13. Horowitz, L. D., V. S. Bishop, H. L. Stone, and H. F. Steigel. 1968. Continuous measurement of internal left ventricular diameter. J. Appl. Physiol. 24:738-744.

14. Theroux, P. D., D. Franklin, J. Ross, and W. S. Kemper. 1974. Regional myocardial function during acute coronary artery occlusion and its modification by pharmacologic agents in the dog. Circ. Res. 35:896-908.

15. Theroux, P., J. Ross, D. Franklin, W. S. Kemper, and S. Sasayama. 1976. Regional myocardial function in the conscious dog during acute coronary occlusion and responses to morphine, propranolol, nitroglycerin, and lidocaine. Circulation. 53:302-314.

16. Weisfeldt, M. L., H. E. Sculley, J. Frederickson, J. J. Rubenstein, J. M. Pohost, E. Beierholm, A. G. Bellow, and W. M. Daggett. 1974. Hemodynamic determinants of maximum dP/dt and periods of diastole. Am. J. Physiol. 227:613-621.

17. Weiss, J. L., J. W. Frederickson, and M. L. Weisfeldt. 1976. Hemodynamic determinants of the time course of fall in canine left ventricular pressure. J. Clin. Invest. 58:751-760. 
18. Weisfeldt, M. L., J. L. Weiss, J. T. Frederickson, and F. C. P. Yin. 1980. Quantification of incomplete left ventricular relaxation: relationship to the time constant for isovolumic pressure fall. Eur. Heart J. 1(Suppl A):119-129.

19. Craig, W. E., and J. P. Murgo. 1980. Evaluation of isovolumic relaxation in normal man during rest exercise and isoproterenol infusion. Circulation. 62(Suppl 2):92. (Abstr.)

20. Raff, G. L., and S. A. Glans. 1981. Volume loading slows left ventricular isovolumic relaxation rate. Circ. Res. 48:813-824.

21. Carrol, J. D., O. M. Hess, H. O. Hirzel, and H. P. Krayenbuehl. 1983. Exercise-induced ischemia: the influence of altered relaxation on early diastolic pressures. Circulation. 67:521-528.

22. Martin, G., J. V. Gimeno, J. Cosin, and M. I. Guillem. 1984. Time constant of isovolumic pressure fall: new numerical approaches and significance. Am. J. Physiol. 247(Heart Circ. Physiol. 16):H283H294.

23. Mirsky, I. 1984. Assessment of diastolic function: suggested methods and future considerations. Circulation. 69:836-840.

24. Morad, M., and E. L. Rolett. 1972. Relaxing effect of catecholamines on mammalian heart. J. Physiol. (Lond.). 244:537-558.

25. Winer, B. J. 1971. Statistical Principles in Experimental Design. McGraw Hill Co., Inc., New York.

26. Brutsaert, D. L., F. E. Radamakers, and S. U. Sis. 1984. Triple control of relaxation: implications in cardiac disease. Circulation. 69: 190-196.

27. Kumada, T., J. S. Karliner, H. Pouleur, K. P. Gallagher, K. Shirato, and J. Ross. 1979. Effects of coronary occlusion on early ventricular diastolic events in conscious dogs. Am. J. Physiol. (Heart Circ. Physiol.)6:H542-H549.

28. Karliner, J. S., M. M. LeWinter, F. Mahler, R. Engler, and R. A. O'Rourke. 1977. Pharmacologic and hemodynamic influences of the rate of isovolumic left ventricular relaxation in the normal conscious dog. J. Clin. Invest. 60:511-521.

29. Serruys, P. W., R. W. Brower, H. J. ten Katen, A. H. Bom, and P. G. Hugenholtz. 1981. Regional wall motion from radioopaque markers after intravenous and intracoronary injections of nifedipine. Circulation. 63:584-591.
30. Marcus, M. L. 1983. The coronary circulation in health and disease. 1. Anatomy of the Coronary Vasculature. McGraw Hill Co., Inc., New York.

31. Katz, A. M. 1979. Role of the contractile proteins and sarcoplasmic reticulum in the response of the heart to catecholamines. Adv. Cyclic Nucleotide Res. 11:303-343.

32. Tada, M., T. Yamamoto, and Y. Tonomura. 1978. Molecular mechanism of active calcium transport by sarcoplasmic reticulum. Physiol. Rev. 58:1-79.

33. Fleckenstein, A. 1977. Specific pharmacology of calcium in myocardium, cardiac pacemakers and vascular smooth muscle. Annu. Rev. Pharmacol. Toxicol. 17:149-166.

34. Parmley, W. W., and E. H. Sonnenblick. 1969. Relation between mechanics of contraction and relaxation in mammalian cardiac muscle. Am. J. Physiol. 216(5):1084-1091.

35. Brutsaert, D. L., N. M. DeClerck, M. A. Goethals, and P. R. Hausmans. 1978. Relaxation of ventricular cardiac muscle. J. Physiol. (Lond.). 283:469-480.

36. Grassi de Gendi, A. O., A. D. Perez Alzueta, and H. E. Cingolani. 1977. Effect of isoproterenol on relation between maximum rate of contraction and maximal rate of relaxation. Am. J. Physiol. 233:H404-H409.

37. Petru, M. A., M. H. Crawford, S. G. Sorensen, T. K. Chaudhuri, S. Levine, and R. A. O'Rourke. 1983. Short and long term efficacy of high dose oral diltiazem for angina due to coronary artery disease: a placebo controlled randomized double blind crossover study. Circulation. 68:139-147.

38. Lorell, B. H., and W. H. Barry. 1984. Effects of verapamil on contraction and relaxation of cultured chick embryo cells during calcium overload. J.A.C.C. 3:341-348.

39. Henry, P. D., R. Shuchleib, J. Davis, E. S. Weiss, and B. E. Sobel. 1977. Myocardial contracture and accumulation of mitochondrial calcium in ischemic rabbit heart. Am. J. Physiol. H677-H684.

40. Bourdillon, P. D., B. H. Lorell, I. Mirsky, W. J. Paulus, J. Wynne, and W. Grossman. 1983. Increased regional myocardial stiffness of the left ventricle during pacing-induced angina in man. Circulation. 67:316-323. 